\title{
METHOD OF EFFECTIVE SPRAYING PLANTS WITH DROP CHARGE OF FERTILIZER SOLUTION BY IONIZED AIR
}

\author{
Sergey Antonov, Gennady Nikitenko, Andrey Adoshev, Sergey Dorozhko, Igor Devederkin \\ Stavropol State Agrarian University, Russia \\ antonov_serg@mail.ru, nikitenko_gv@mail.ru, adoshev@mail.ru, dev6307@yandex.ru, \\ devederkin@mail.ru
}

\begin{abstract}
A small amount of fertilizers applied during the cultivation of the soil or their complete absence leads to a decrease in the crop yields. To increase the yield of the plants, one can apply foliar top dressing with fertilizer solutions. Its main advantage is the rapid delivery of nutrients in critical periods of plant development by penetrating them through the leaves. Increasing the effectiveness of foliar top dressing is achieved by enlarging the surface coverage of plant leaves with droplets of sprayed fertilizers, increasing the adhesion of nutrients on the leaves. Existing methods of spraying plants have a number of disadvantages: drops of fertilizer solution adhere to each other and drain from the surface of the sheet; a small amount of solution drops adhere on the back of the sheet; drift of drops of solution by wind during spraying. The proposed method of spraying can eliminate these drawbacks. This is realized by mixing ionized air with a solution for plant fertilization and its subsequent spraying. The liquid-air ionized mixture, when leaving the hydraulic sprayers, is crushed into drops of solution, which receive a charge from the ionized air. Charged drops of fertilizer solution, falling on a plant leaf, adhere to it, as the plants have the opposite charge. Applying this method of spraying plants is possible to reduce fertilizer consumption without reducing the efficiency; increase the efficiency of penetration of fertilizers into plants; increase the number of drops of solution applied to the back of the leaves of plants; reduce the drift of droplets by gusts of wind.
\end{abstract}

Keywords: spraying, fertilization, ionization, drop, voltage.

\section{Introduction}

Fluid spraying is an important process used in chemical protection, as well as for carrying out foliar fertilizing with crops. Important characteristics of the spraying process are the size of the droplets produced, their concentration and spatial distribution.

One of the most promising ways to increase the efficiency of the process of spraying liquid is to pre-saturate it with gas. The use of electrostatic charging of droplets of atomized liquid increases the productivity and the quality of coating plants.

The main principle of the method of electrostatic charging droplets consists in spraying liquid with simultaneous transmission of electric charge to the drops formed, and they are evenly deposited on the object having an opposite charge. There are several ways to charge droplets, but in practice two of them are most often used: ion and contact.

Ion charging is used in devices of electron-ion technology, due to the high efficiency and simplicity of the process. The source of the ions is the corona discharge field, which arises in the space between the two electrodes, shown in Fig. 1, a. The charge arises as a result of the adsorption of ions by the drops of liquid, which arise when ionizing the air. Receiving a charge, the droplets begin to move along the lines of the force of the electric field toward the object being treated [1-3].

Contact charging occurs as a result of the contact of the working fluid solution with the sharp edge of the atomizer, which acts as the corona electrode. The corona discharge arises at the tip of the edge of the electrode, while electric charges flow into the air, shown in Fig. 1, b. If a thin layer of liquid is applied to this edge, it will be charged and under the action of the electric field forces, stretch and drain from the surface in the direction of the object having the opposite charge. With contact charging of drops, the level of charge is 10-30 times greater than when ionic. Charging drops contributes not only to crushing, but also to their directed movement.

The study of the electrostatic spraying process both in Russia and abroad is carried out on the basis of universities with the financing of large firms. In the UK the sprayer APE- 80 is designed. Firm Marwald of Florida (USA) has developed a device KWH "Kinkelder". Firm Farm Machinery Corp. (USA) has created a boom sprayer for field crops. SES company (UK) has created a prefix to the hydraulic sprayer. SADKO company (Ukraine) has developed a manual sprayer GMD-6014. 

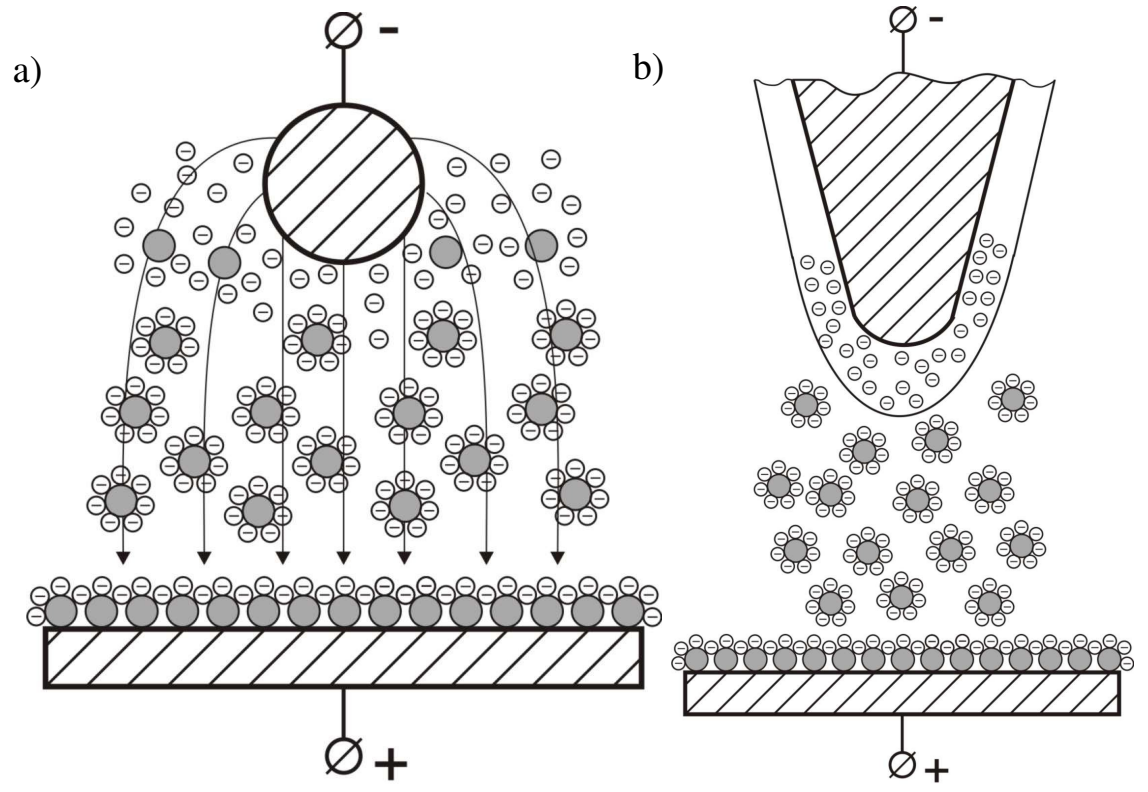

Fig. 1. Scheme of charging drops: $a$ - ionized; $b$ - contact

A review of the technical means for charging the liquid drops has shown that the existing devices do not allow to charge large amounts of sprayed liquid and cannot be used for mobile agricultural machinery according to the requirements of the equipment electrical safety.

\section{Materials and methods}

Spraying plants by standard methods there is a number of problems that affect the efficiency of using means of chemical protection [4]. The main disadvantages of the existing methods are: polydispersity of spray drops, demolition of the drops by wind and low coating density of a plant leaf, adhesion of solution droplets, as a consequence of runoff and contact with soil. All these shortcomings contribute to the large losses of remedies and foliar extra nutrition of plants [5;6]. The proposed method of spraying agricultural crops allows eliminating the listed shortcomings.

The spraying system (Fig. 2.) consists of the sprayer container 1, compressor 2, ionizer 3, high voltage source 4 , pump 5, injector mixer 6 , distributor valve 7 , hydraulic sprayers 8 and the treated plants 9 .

The method of spraying agricultural crops functions in the following way. Solution for the treatment of the plant $(\longrightarrow)$ from the tank of the sprayer 1 is supplied by the pump 5 under pressure via the line injection sprayer to the mixer 6 . The compressor 2 supplies air $(\bigcirc)$ in the ionizer 3 . Under the action of high voltage (not less than $14 \mathrm{kV}$ ) generated by the high voltage source 4, the passing air is ionized $(\odot \rightarrow$ ) by a predominantly negative charge. The high voltage source 4 converts the voltage of the onboard system of the mobile equipment $(12 \mathrm{~V})$ to high voltage (minimum $20 \mathrm{kV}$ ). Ionized air $(\ominus \rightarrow)$ goes into the injection mixer 6 , in which there is mixing of the ionized air $(\ominus \rightarrow)$ and solution for treatment of plants $(\longrightarrow)$. At the exit of the injection mixer 6 ionized liquid-air flow is obtained $(\ominus)$, which enters the distributor valve 7 . The distributor valve 7 directs the ionized liquid-air flow $(\ominus \rightarrow$ ) through the ways of the sprayer to the hydraulic sprayers 8 . At the exit from the hydraulic sprayers 8 the ionized liquid-air flow $(-\rightarrow$ ) breaks up into liquid drops of solution for treatment of plants with bubbles of ionized air, which transmit its charged drop solution for the treatment of plants.

Charged droplets of solution for processing plants $(\rightarrow)$ falling on a plant 9 that has a positive charge, because it is connected to a positive electrode of a high voltage source 4 , are evenly distributed on the surface, increasing the processing surface.

The method for spraying crops with a plant treatment solution, with ionized air supplied, and producing an ionized air-liquid mixture, is based on the fact that the air supplied to the injector mixer is pre-ionized and the ion concentration must be in the range of $500 \times 103 \mathrm{~cm}^{-3}$ to $5000 \times 103 \mathrm{~cm}^{-3}$, and then it is mixed with the solution for processing plants and is brought to hydraulic sprayers, at the 
exit it is crushed onto the drops of the solution for processing plants and ionized air, which passes its charge to the drop, the drops falling on the treated plants with positive charge increase the processing surface and the uniformity of their distribution.

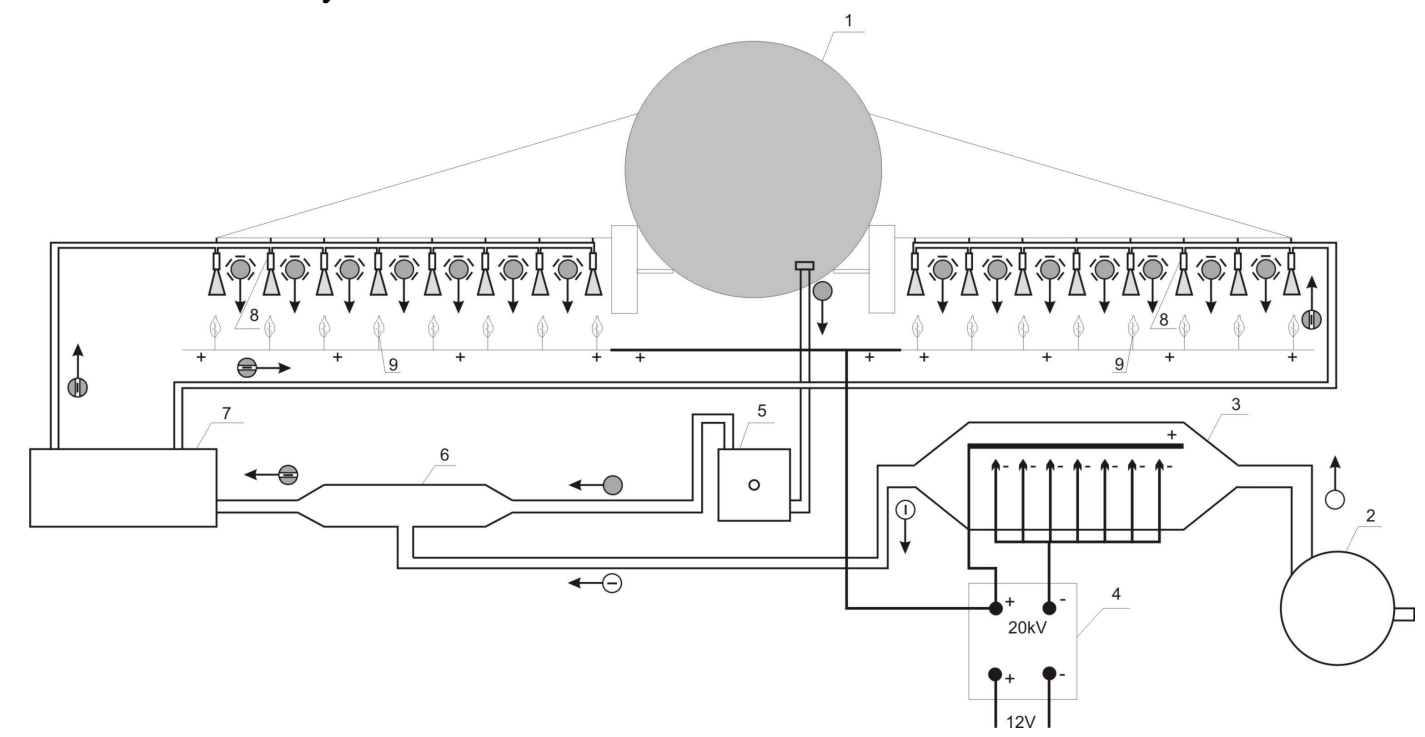

Fig. 2. Method of spraying crops: 1 - tank; 2 - compressor; 3 - ionizer; 4 - high voltage source; 5 - pump; 6 - injector mixer; 7 - valve distributor ; 8 - hydraulic distributors; 9 - treated plants

Rational application of electrotechnology in the field crop production processes makes it possible to improve the efficiency of agrotechnical methods. The use of ionization of a water-air mixture in spraying systems promotes a more rational use of chemical plant protection products.

\section{Results and discussion}

The aim of the study is to determine the parameters of the spray quality and deposition of the charged drops of the fertilizer solution. The collection of spray drops is carried out according to the method of testing sprayers using registration cards $[7 ; 8]$. Covering of registration cards with drops of liquid is fixed by the camera.

a)

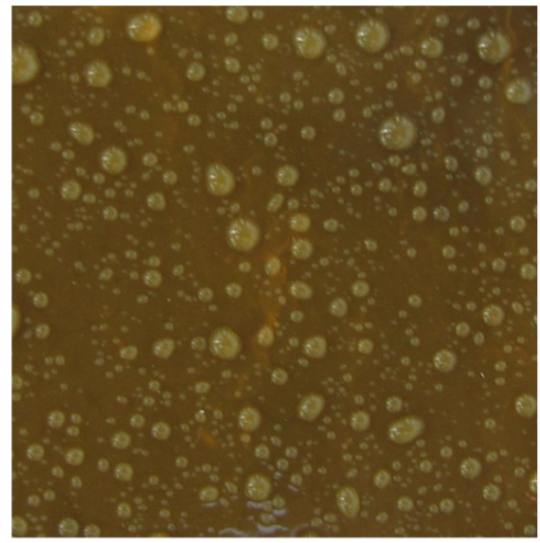

b)

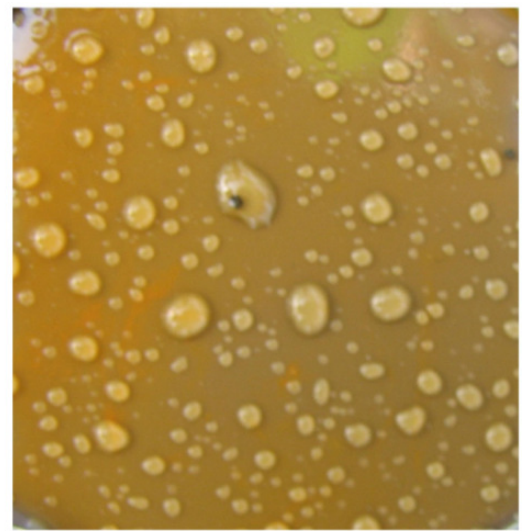

Fig. 3. Density of covering registration cards with drops: $a$ - charged; $b$ - uncharged

To determine the efficiency of spraying plants with a charge of droplets of a solution of fertilizers, voltage was applied to the electrodes of the ionizer $14 \mathrm{kV}, 17 \mathrm{kV}, 20 \mathrm{kV}$ as well as control spraying without charging droplets. The results of the studies are given in Tables 1, 2.

Considering the results obtained, it should be noted that as the voltage on the ionizer electrodes increases, the density of the coating increases with the drops of the registration cards. This indicates an increase in the number of effective droplets on the surface of the sheet and a decrease in its impact on the soil. The greatest increase in the density of the coating of the sheet is noticeable at voltages of 17 , $20 \mathrm{kV}$ and is from 57 to $150 \%$. When the voltage increases, an increase in the number of droplets of less than $100 \mu \mathrm{m}$ occurs. Small drops quickly ionize and are more susceptible to the influence of the 
Coulomb forces of the external electric field of the plant, so they preferentially settle on the back side of the sheet, where large drops under the action of inertial forces cannot get.

Table 1

Distribution of drops by size groups for the front side of the sheet

\begin{tabular}{|c|c|c|c|c|c|c|c|}
\hline \multirow{2}{*}{ Voltage, $\mathrm{kV}$} & \multicolumn{6}{|c|}{ Size group, mkm } & \multirow{2}{*}{ Total, th } \\
\hline & $20-50$ & $50-80$ & $80-100$ & 100-150 & $150-200$ & $>200$ & \\
\hline 0 & 6 & 8 & 15 & 41 & 30 & 32 & 133 \\
\hline 14 & 7 & 13 & 22 & 40 & 33 & 26 & 141 \\
\hline 17 & 21 & 37 & 56 & 61 & 33 & 46 & 255 \\
\hline 20 & 10 & 18 & 37 & 49 & 53 & 45 & 212 \\
\hline
\end{tabular}

Distribution of drops by size groups for the back side of the sheet

Table 2

\begin{tabular}{|c|c|c|c|c|c|c|c|}
\hline \multirow{2}{*}{ Voltage, $\mathrm{kV}$} & \multicolumn{6}{|c|}{ Size group, mkm } & \multirow[b]{2}{*}{ Total, th } \\
\hline & $20-50$ & $50-80$ & $80-100$ & $100-150$ & $150-200$ & $>200$ & \\
\hline 0 & 0 & 10 & 17 & 20 & 17 & 11 & 75 \\
\hline 14 & 10 & 12 & 20 & 18 & 25 & 19 & 104 \\
\hline 17 & 20 & 39 & 40 & 31 & 22 & 14 & 166 \\
\hline 20 & 22 & 40 & 48 & 35 & 26 & 19 & 191 \\
\hline
\end{tabular}

According to the recommendations for different types of biologically active preparations and different cultures, the optimal droplet size during application varies from 80 to $200 \mu \mathrm{m}$. Given the specified range of droplet sizes, it can be concluded that the obtained data satisfy the technological requirements. Speaking about changing the diameter of liquid droplets, we can say that with increasing voltage on the electrodes, the size of the drops falling on the front side of the leaf decreases and increases for the back side.

\section{Conclusions}

To increase the effectiveness of spraying plants, it is recommended to use the electrostatic charging method. This method allows obtaining a high accuracy of coating dosage of the plant leaf at high speeds of the sprayer. The supply voltage of the ionizer must be at least $14 \mathrm{kV}$.

As a result of the carried out research on the deposition of charged drops, it can be concluded that the consumption of the fertilizer solution is reduced (up to 54 liters per ha), the losses of chemicals are reduced, and the pollution of the environment is reduced.

It should be noted that as the voltage on the electrodes increases, the density of the coating increases with drops of the plant leaf. This effect is brightly expressed on the back of the leaves.

\section{References}

[1] Лёб Л. Статическая электризация (Static electrification). M. -L. - Gosenergoizdat. - 1963, 405 p. (In Russian).

[2] Турчин И.А. Электризация рабочих жидкостей (Electrification of working fluids). // Journal of Plant Protection. - №9. - 1987, pp. 29-36. (In Russian).

[3] Nasr G.G., Yule A.J., Bendig L. Industrial Sprays and Atomization: Design, Analysis and Applications. Springer-Verlag London, 2002. 501 p.

[4] Антонов С.Н. Анализ существующих методов защиты растений (Analysis of existing methods of plant protection). / Methods and technical means to improve the efficiency of electrical equipment in industry and agriculture: a collection of scientific papers on the materials of the 82nd Scientific and Practical Conference of the Electric Power Department of Stavropol State University (Stavropol, 12.09.05.12.2016.). Stavropol: AGRUS, 2016, pp. 296-298. (In Russian).

[5] Архипов В. А. Аэрозольные системы и их влияние на жизнедеятельность (Aerosol systems and their influence on vital functions) / V.A. Arkhipov, U. M. Sheremetyeva. - Tomsk: TPU Publishing House, 2007, 136 p. (In Russian). 
[6] Matthews G.A. Pesticide Application Methods. 3rd ed. - Wiley-Blackwell Science Ltd., 2000. $448 \mathrm{p}$.

[7] ГОСТ Р 53053-2008 Машины для защиты растений. Опрыскиватели. Методы испытаний (GOST R 53053-2008 Machines for the protection of plants. Sprayers. Test methods). (In Russian).

[8] Avdeeva V.N., Antonov S.N., Molchanov A.G., Devederkin I.V. Disinfecting of winter wheatgrain withelectrophysical factors. Engineering for rural development, Jelgava Latvia, 2017, pp. 323-327. 